\title{
Interpreting the Impact of Ogho Dance of Umundugba People in Imo State Towards Peace Building
}

\author{
AKAS, NICHOLAS .C \\ Department of Theatre \& Film Studies, Nnamdi Azikiwe University, Awka
}

\begin{abstract}
Dance and its use has become an indispensable tool in our indigenous communities no doubt. But the main problem is that indigenes or some myopic citizens do not see anything communicative in dance or as a corrective tool for peace building, rather they view it as mere means of cultural identification, sustainability and transformation only without looking beyond these. This paper strongly aims to restate that dance is and still remain a socio-corrective tool that mirrors the society and proffers solution through its choreographic styles which lampoons, appreciates or serves as a watchdog. The use of Ogho dance in paper as a tool for peace building objectively interprets its choreographic styles as: a watchdog in the daily activities of Umundugba people, b: as a tool against injustice of any sort, c: as a connecting link between the ruler and the ruled. From findings Umundugba people have viewed and appreciated their performance as mere entertainment only, but the socio-communicative essence embedded in choreographic styles which is always de-emphasized proved otherwise, thereby forming the basis of this paper. To ascertain this through qualitative research methodology, content analysis and liberal peace theory as theoretical frame work was used. In conclusion, Dance through its choreographic styles has gone beyond aesthetic assembling of movements into serious corrective tool for peace building.
\end{abstract}

DOI: $10.7176 /$ RHSS/9-1-08

\section{Introduction}

Dance has remained unique art form that passes the communal message whenever it exists. It always mirrors the immediate environment and proffer a possible solution towards any existing problem. At this point, dance and its use become instructive, interrogative and communicative. Laban as cited by Erice Rose Jeffrey maintained that "Dance utilizes an interactive inclusive learning approach to enhance awareness of participants' motor, cognitive and expressive abilities" (24)

Bergmann Drave as cited by Jeffrey further concurred that:

Dance allows us to communicate evolving understandings of ourselves and the world through movement and requires participants to exercise their imaginations, to think and to solve problem (24)

Dance as a communicative art helps in x-raying situations or conditions that lend to its creation. In performance, choreographed dance are not done out of mere assumption or for exhibition styles, rather some events, legends, myths or rituals gave rise to its form, style and content. Anne Green Gilbert advocates that: "In communicative dance approach, indigenes explore ideas and generate their own comm.-mythic movement for effective interpretation rather than learning set choreographed steps". (4)

The effectiveness of dance seizes to be exhibition of skills more especially when it involves choreography. The aim of choreography in dance is to utilize both the available space and dancer's body in presenting the subjective truth in the performance. It is subjective in the sense that beyond generalized perception of entertainment lies the idealized socio- problems that requires urgent attention. Akas Nicholas observed that:

Dance helps to transform the visual appreciative eyes of the audience into critical interpretative eyes of seeing performances as tool for identifying problems, analyzing the problems and accept the final outcome as the possible way forward.

The use of iconic movements or signs in dance serves as interconnecting link between the ruling and the ruled, though entertainment seems inevitable but dancer's body becomes a tool in passing the intended messages across to the appropriate channel for a redress. Roxane Fenton opines that: "The usefulness of dance in the society is beyond entertainment rather constitutes as an indirect reinforcement of proper roles in society. For instance relationships to rulers, to the gods and to the governed (119)"

The beauty of every well choreographed dance(s) is to understand the unique intended message. Such messages when indentified and situated properly attract the owners close to the performance. The usefulness of dance at this point becomes corrective (to stop conflicts) or aggressive (to encourage revolts either peaceful or destructive). Akas stated that "What makes dance performance useful is the ability of the audience to see themselves being reflected in the performance"(4). 


\section{The Dancer's Body and its Essence}

The dancer's body serves as the choreographers' interpretative tool. The choreographer looks at the body beyond flexibility rather begin to imagine creatively how it would be use to achieve the actual aim. Claudio Kogon observes that" "The body is a natural form of self-expression and so does the spirit. It also expresses how free we actually are and highlighting the restrictions our minds impose on it" (4).

Kogon further maintain that:

Dancer's body is the art tool in which human movement becomes the medium for seeing, understanding, communicating ideas, feelings and experiences. It has its own content, vocabulary; skills and techniques which must be understand and applied to be proficient in the arts (3).

The dancer's body during performing seizes to be his or hers rather a highly classified working tool. It is seen as classified in the sense that through choreographic styles the body is use for the following:-

a. It is always available

b. It accepts there is a problem

c. It is used as an interrogative tool

d. Passes through different formations or organization while seeking for solution

e. Serves as an unconditional representational zone (iconic tool for solution).

\section{Choreographic Theories}

The essence of choreographic theories especially in this paper is to portray dance, choreographers and their styles as a serious corrective measure. Kogon states that: "No real creative choreographic work emerges out of assumption rather one or two theories motivate his/her improvised muse. (24)". Goodman in his own view states that:

Dance is not a language, since it has no grammar or syntax, but that it is language like or lingual since it is an expression (what he calls utterance) of a human person or self with culturally embedded and art relevant properties that can be perceived and understood as such by other. (36).

Kogon presents those choreographic theories as;

a. Subjectivist theory

b. Natural theory

c. Expressionist theory

d. Semiotic theory

\section{a. Subjectivist Theory}

This theory maintained that expression in dance exposes the innermost feelings of dancers performing on stage.

b. Natural Theory

This theory deals on how and dancer moves his body while performing.

c. Expressionist Theory

This theory also maintained that the level of expression in every dance depends on the content.

\section{d. Semiotic Theory}

This theory strongly states that it is formal choreographic structure of dance that makes it expressive.

The above theories when applied in choreography, it always present dance as a unique tool for sociocommunicative, socio-interpretative and socio -interrogative.

\section{Theoretical framework}

Dance through its choreographic styles has remained a unique act form that is harmless, not destructive nor dehumanizing at any point in time. It takes its communicative value closer to its own in order to awaken their consciousness morally, spiritually and socially, thereby using materials within its immediate environment as working metaphor. The choreographer does not choreography just to victimize people rather his/her core aim is to lampoon, criticizes and constructively redirected people's mind and opinion towards an alternative survival measures.

The major set goal cum target of every choreographer is Man and Society. Man becomes the key factor because he is at the receiving end (of poverty, killing, low standard education, no electricity, bribery and looting), so he struggles seriously to survive either positively or negatively, while society as the second key factor has really work against all odds because of individualism, tribalism, status and uncontrollable quest for more money, all these motivates the choreographer's choreographic intention. Dance as non-verbal means of communication gives it the required freedom of expression based on expressionist theory as stated earlier where what matters most is the content. It is through content that the harmless intension of the choreographer is been 
passed across on like in drama where thoughts/actions are been misinterpreted to be too personalized and aggressive.

Base on the aforementioned, this paper would based its theory on Liberal Peace Theory. The Liberal Peace Theory was propounded by Rawls J. it simply states that:-

It is a common good idea of justice that assigns human rights to all its members; its

basic structure includes a decent consultation hierarchy that protects these and other

rights and ensures that all groups in society are decently presented by elected bodies

in the system of consultation (50)

Liberal peace theory gives creative work of arts (especially dance) freedom to always interrogate situations of things peacefully and not forcefully, thereby presenting creative arts as people oriented ideology and not selfish interest for favoritism or popularity. Rawl as cited by John Mac Millan observed that: "The aim of liberal peace theory through communicative medium centers more on people and content rather than states or benefits (24)". Millan further maintained the use of liberal peace theory through creative arts: "strikes the right balance between liberty and equality through giving priority to basic rights, liberties and opportunities but also by assuring that citizens have the means to "make intelligent" and effective use of their freedoms". (184)

It is on this basis that this paper especially while analyzing Ogho dance performance of Umundugba would anchor all the arguments on Liberal Peace Theory.

\section{Dance and peace building}

The communicative value imbedded in dance till now has made it a corrective tool. It is the corrective nature of dance base on its societal relevance that draws people to watch it subjectively and not objectively. Rama Mani as cited by Dorota Piotrowska suggested that: "Dance and Peace building are means to pursue a more inclusive approach to justice who would take into account not only direct victims and perpetuators but also bystanders and the population at large" (15).

Peace building is the core aim of every society, community or country. The joy of every human existence is to have peaceful co-existence such as to sustain custom, rules and regulations. Ayindo as cited by Jeffery states that: "the performing arts have been key components in the making culture and passing down values as embodied expression of our humanity, emotions and imaginations" (20).

Over the years, people (leaders) have tired preaching peace orally and through organizing of workshops/seminars without utilizing the art (dance) as a communicative medium, rather ironically they choose to use art (dance) as a mere process to lighten up the environment during occasion which is culturally degrading. Akas submitted that: "dance has and still remains the harmless tool to preach hardcore peace building beyond entertainment without party(s) involve not seeing it as been too personalized" (18).

Peace building through dance makes both the choreographer and dancers' social crusades that use societal issues as choreographic metaphors. In this paper, the researcher strongly debunk that the use and essence of dance as all comers affairs rather stated that professionalism should be the order of the day. In using dance as corrective measure for peace building, the choreographer considers the following:

a. Who are the people involved

b. What are they struggling for

c. Could it be achieved? and if no what is the possible way out.

d. How will the above be actualized without been emotional or personalized

These and more is what dance does towards Peace building. Cohen, Gutierrez Varea and Walker as cited by Jeffery observed that:

Through dance there is he opportunity for expression of silenced words and suppressed actions, the nourishing, repair and development of capacities which may have been affected by conflict and providing increased nuance, complexity and texture towards understanding concepts of peace building (172).

Peace building cannot be achieved orally only without using creative tools like music, dance or film as interpretative reflective pointer. A Chinese adage said 'Children tend to retain and reoccur more through visuals them reading".

\section{Summary of Ogho dance of Umundugba people}

This is an annual festival preformed yearly in Umundugba Isu Local Government Area, Imo state. It is a very symbolic dance among the indigenes. In other to portray its symbolic nature is been perform between June to July every year. The iconic months represent two things.

A. It reminds the community the period the first woman was taught the dance by a marine spirit. The marine spirit pleaded that the dance must be guided with all sense of sacredness. According to Mr. Onyeama (in an interview) "The dance steps where very difficult and complex to be learnt by the women, so men in the community hijacked it and gave the women a more simple dance steps'. He also 
said 'to show that women are the originators any girl born during the month of the performance automatically becomes an initiate and addressed as Echerere (meaning a Special Queen or the chosen one).

B. Secondly, it is period of farming were farmers seeking for the divine intervention of their ancestral fathers to give them a bountiful harvest. But beyond these, one thing is indispensable which is the content of the performance where is seen as a tool for peace building in the community. One may ask what the meaning of the name. The name simply means 'Ogho Mmiri" (A dance from the water). So because of where it emerged from the dance is highly respected, valued and cherished. It is important to note according to Mr. Emeka Akamere (in an interview) "It is the costumes of dancers inform of masquerades that depicts the various situations at hand". He went further to say "The dancers" are not expected to dance much but their costumes especially in colours speak volume". He also added that peaceful nature of the dance and its costumes are classified as follows;
a. Ike Mba
b. Ugo Ulo
c. Uzo di n’ Mba

\section{Ike Mba}

This is the most feared masked dancer among others. It is believed cosmologically to be in two forms halfhuman and half spirit. The costume is always Black which symbolically shows danger. The masquerade dancer only performs or appears whenever there are serious inter-communal disputes. According to Onyeama "It is of their believe in Umundugba that any issue not settled by this masquerade dancer would not be settled again". Before he appears the communities involved in the conflicts would be settled four hours before. The time four hours is very symbolic in the sense that being half human and spirit, he would be seeking for divine wisdom and logical reasoning from their ancestral fathers, while the communities involved during this period would be under sections tension. Symbolically, while wanting for the response a slow and solemn music would be playing at the background showcasing uncertainty. Once the Ike Mba masked dancer is through with the divine consultation, he appears to the arena with an iconic cane in his hand. This cane interpretative shows that communities involved are forgiven and warned not to commit such offence again. But though forgiven they must be punished a little (through fine) on the gravity of their offense. The fine at times varies such as; cow, twenty thousand, tubers of yam, labour or childlessness. But in situation whereby he appears without the iconic cane, it simply means the ancestral world are yet to pass their final verdict.

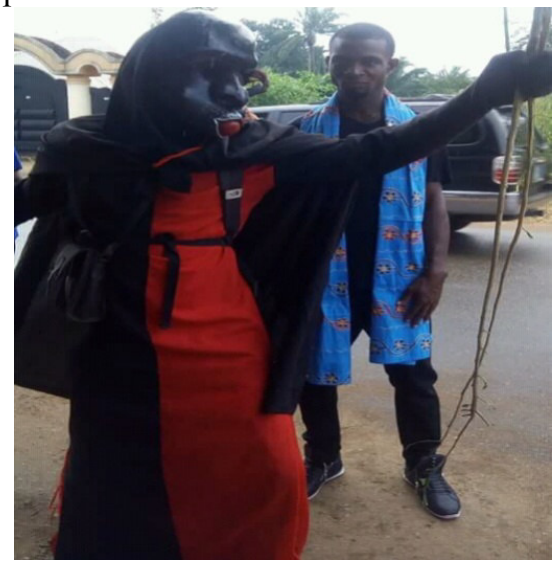

Plate 1: Ike Mba with the sacred cane for peace judgment. 


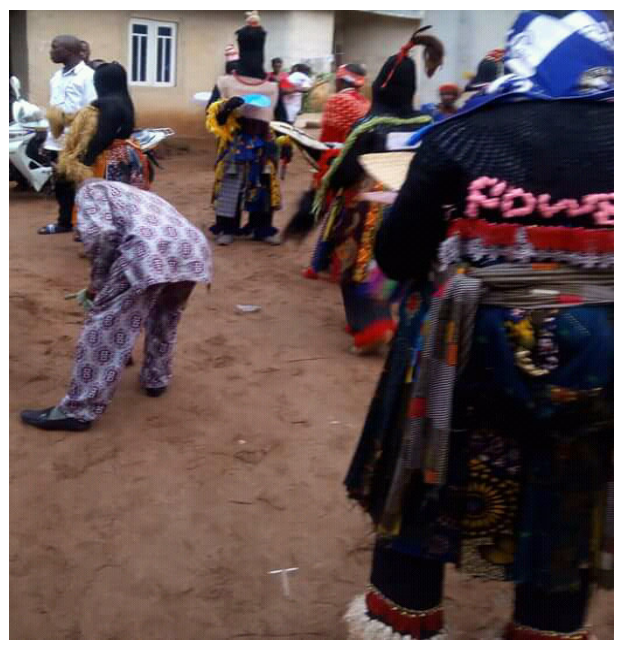

Plate 2: Ike Mba in a worrisome costume.

According to Mr. Ihechinulo (in an interview) states that 'Though we have the modern court for settling issues Ike Mba verdicts especially in his costumes is highly respected' To showcase that the issues have been settled both in human and spirit world he will perform a symbolic circular movement. The circular movement according to Mr. Ogu (in an interview) said "Though the offenders might be freed with the judgment and fine. But if found wanting again, they might be in full of regrets".

\section{Ugo Ulo}

This masquerade dancer here with its costumes embodies peaces and roll call of good deeds. Like the researcher said earlier through an interview that the costumes speak more that movements in Ogho dance. The costume used here is multi-coloured which show the unpredicted nature of man. It also advocates the following;

a. Trust

b. Understanding

c. Giving

According to Mr. Onyeama "Once this masquerades dancer appears with its multi-coloured costumes, the bag bear will start a song where he calls the names of those who have contributed positively in the community, while those who did not do anything in helping others would be lampooned". He also added that for one's name to be mentioned in the song is strictly on merit. The masquerade dancer iconic prop for the performance is a walking stick which reminds those that does not help others that;

a. Nobody is an island

b. One day their money and strength will fail them, all they require for support is the walking stick. So they are always encouraged to do well.

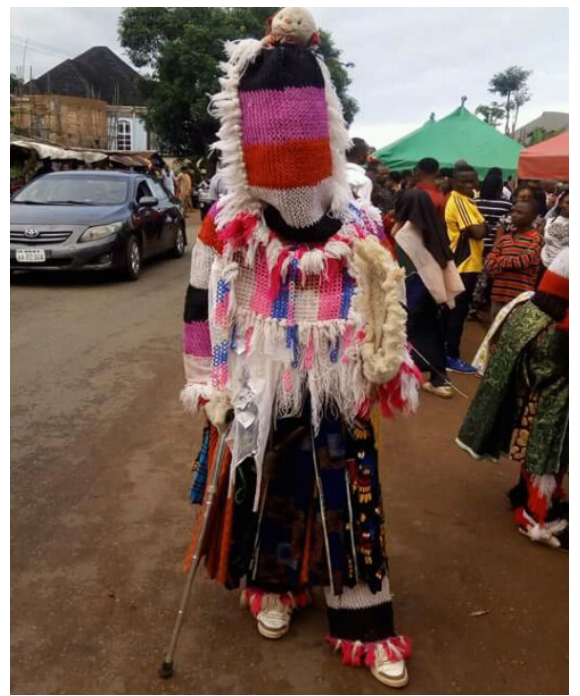

Plate 3: The masked dancer on his full costume with the iconic walking stick.

\section{Uzo Di n' Mba}

The masquerade dancer costume here is white and the dance formation in twos. The white costumes encourages 
the indigenes to be peaceful, love each other and be progressive minded. It is also believed through the white costume that people with good intentions attracts favour to themselves and their generations to come. The two formation choreographic style reminds the indigenes that nobody knows tomorrow. So everybody is required to be of good behaviour in order to be valued and appreciated by others. It also encourages the indigenes to be detribalized in all its ramification rather begin to appreciate one another.

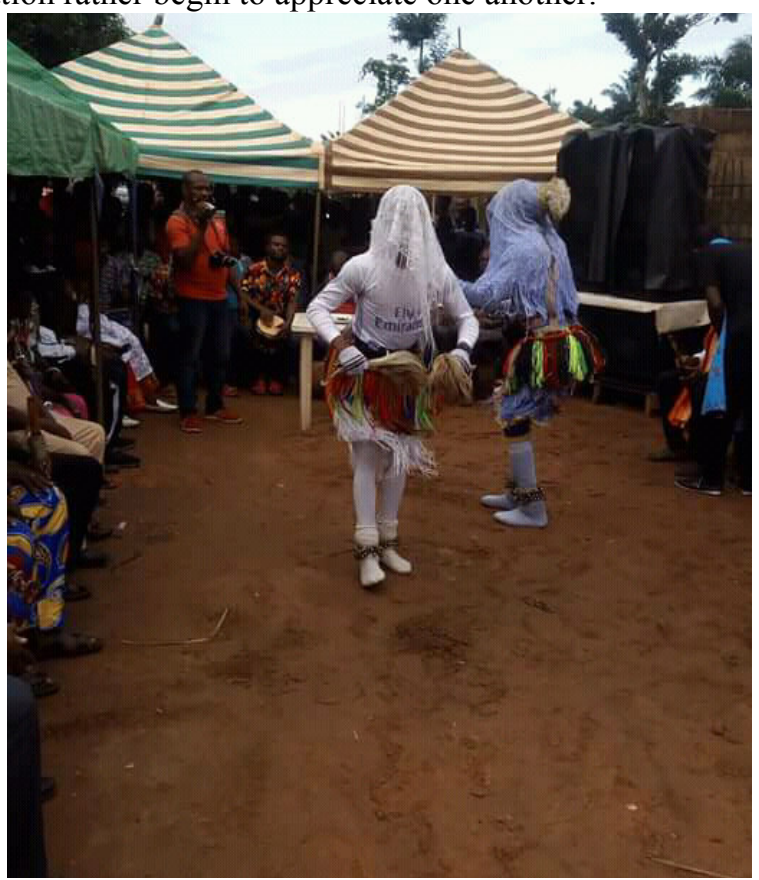

\section{Conclusion}

From the findings in this paper, the researcher can comfortably state that the aim of every dance through its choreographic styles is to mirror, communicate and awaken people's consciousness. The situations of things in Nigeria is becoming too alarming and demands an urgent attention especially in peace building and say no to any form of killing. Peaceful co-existence in any community, state or country attracts foreign inventors and open room for tourism thereby boosting the country's economic status. But in order to achieve the reacquired peace building, creative medium must be used (dance). Where the ruled and ruling though entertained but through communicative choreographic styles the ideal message is bee passed across accordingly. This paper finally suggest that choreographers should always take the driver's seat and see themselves as communicators cum agent of peace building and not mediocre whose sole aim is "Smiling to the bank syndrome only".

\section{Works Cited}

Akas Nicholas. Implication of Objection women in Nigerian Dance video: A study of Timay's BumBum, Preorcjah Vol 2 91) 2017.pp 58 - 71

Clandio Kogon. Dance as a tool for creativity with young people. USA: University Press. 2013.

Dorota Piotrowska. The Value of Culture in peace building - Examples from Democratic Republic of Congo, Yemen and Nepal New York: (Published Master's Thesis) 2015.

Erica Rose Jeffrey. Dance in Peace building: Space, Relationships and Embodied Interactions (Published Ph. D Thesis) 2017.

Gilbert Anne Green. Creative Dance for all ages: A conceptual Approach . U.S.A; University Press. 1992.

Macmillan John R. Liberalism and the Democratic Peace, Journal of International Studies, 2004.pp 179 - 200

Mr. Onyeama (Interviewed $3^{\text {rd }}$ August 2018)

Mr. Emeka Akamere (Interviewed $4^{\text {th }}$ September 2018)

Mr. Ihechin'ulo K (Interviewed $27^{\text {th }}$ October, 2018)

Rawls J. Laws of people. New York: Cornell University Press. 2001.

Roxane Fenton. Dirty Dancing, Dance, Class And Race In The Pursuit Of Womanhood. Oxford: Oxford University Press. 2012 